\title{
MUDANÇAS CLIMÁTICAS \\ FENÔMENOS CLIMÁTICOS ESTÃO RELACIONADOS Á PRODUÇÃO DE CULTURAS ANUAIS? ESTUDO DE CASO EM TIBAGI-PR
}

\author{
Ana Flávia Bilmayer - ana-bilmayer@ hotmail.com \\ Universidade Tecnológica Federal do Paraná - Campus Campo Mourão. \\ Guilherme Gobbi Teixeira - guilhermegob@gmail.com \\ Universidade Tecnológica Federal do Paraná - Campus Campo Mourão. \\ Paulo Agenor Bueno - pauloaabueno@gmail.com \\ Universidade Tecnológica Federal do Paraná - Campus Campo Mourão.
}

\begin{abstract}
Resumo: A agricultura é responsável por grandes exportações e gerações de emprego no Brasil, fato que aumenta o vínculo do homem com esta atividade que é altamente vulnerável as alterações climáticas. Tibagi-PR se destaca na produção de milho, trigo e aveia e está localizado em uma área de volumes elevados de precipitação. Esta pode ser influenciada, na maioria das vezes, por fenômenos climáticos como o ENOS, que é composto por duas fases, o El Niño caracterizado pelo aquecimento das águas superficiais do Oceano Pacífico Tropical e a La Niña, fase fria, qualificada como o resfriamento das águas marítimas. Tem-se como objetivo deste trabalho a exploração estatística dos dados pluviométricos no decorrer de 20 anos no município de Tibagi-PR, comparando-os no referido período, bem como verificando a possível relação com a produção agrícola anual de milho, trigo e aveia. Através do teste de variância de Kruskal-Wallis foi possível aferir a magnitude entre os volumes de precipitação e por meio da correlação linear de Pearson pôde-se estimar a relação das culturas com as precipitações. No entanto, verifica-se que o município não sofre com nenhuma dessas interferências. Outros fatores podem estar relacionados ao desenvolvimento da produção desses cultivos, como a generalidade do IOS que pode não ser aplicado a algumas regiões, a curta série histórica analisada ou ainda os altos volumes de precipitação do munícipio.
\end{abstract}

Palavras-chave: Fenômenos climáticos, Produção agrícola, Estatística.

\section{INTRODUÇÃO E OBJETIVOS}

A agricultura tem contribuído há séculos para a criação, conservação e disponibilidade de uma variedade de hábitats seminaturais, moldando a maior parte das paisagens do mundo. Ela também sustenta uma comunidade rural variada que constitui a base cultural de cada povo e desempenha um papel importante na manutenção do equilíbrio e da saúde ambiental (BEYRUTH, 2008). Atualmente tem-se na agricultura a maior responsabilidade pelas exportações e geração de emprego no Brasil, fato que aumenta o 

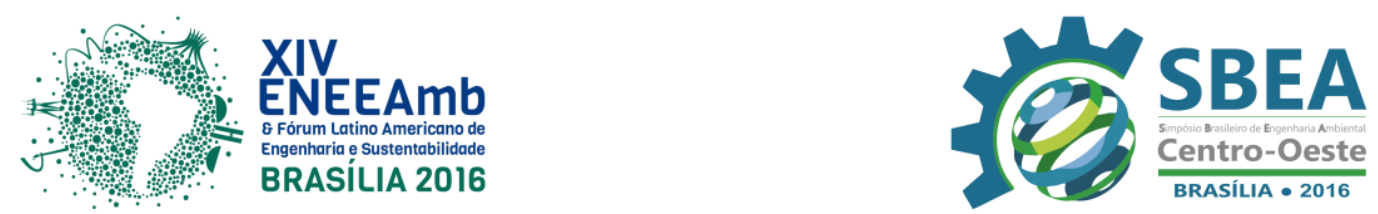

vínculo do homem com esta atividade que é altamente vulnerável as alterações climáticas (SILVA et. al, 2009).

As características climáticas, como precipitação, temperatura, radiação solar, ventos, podem exercer influência sobre todos os estágios da produção agrícola, determinando desde quais atividades serão desempenhadas até a seleção de regiões ou lugares para a instalação de culturas e experimentos agrícolas, além de servir como planejamento a longo ou curto prazo das referidas atividades (SILVA, 2013). As mudanças climáticas podem afetar os sistemas agrícolas regionais com sérias consequências, dependendo de como as mudanças acontecem, determina-se a viabilidade e a utilização dessas áreas. As chuvas, assim como a falta delas, estão relacionadas com fenômenos meteorológicos pertencentes às várias escalas temporais e espaciais, que vão desde a escala global como El Niño e La Niña, às condições locais, como chuvas localizadas (FERREIRA, 2005).

Segundo o Instituto Nacional de Pesquisas Espaciais - INPE (2015), o fenômeno de El Niño-Oscilação Sul (ENOS) é caracterizado pelo aquecimento descontrolado das águas superficiais do Oceano Pacífico Tropical a partir dos ventos, afetando consequentemente o regime da chuva em regiões tropicais e de latitudes médias, enquanto a La Niña representa a fase fria do fenômeno, apresentando características opostas ao El Niño, havendo o resfriamento nas águas superficiais do Oceano Pacífico Tropical. De acordo com Galvani et. al (1998) as intensidades desses fenômenos foram classificadas como fraca, moderada e forte, usando o Índice de Oscilação Sul - IOS que é determinado a partir da diferença entre os desvios de Pressão atmosférica ao Nível do Mar (PNM) registradas nas estações meteorológicas do Taiti, no Pacífico Central e Darwin, no norte da Austrália.

De acordo com Silva (2013), na Região Sul do Brasil, observa-se abundância de chuvas nos anos de El Niño e estiagem em anos de La Niña. Apesar de a influência dar-se durante todo o período de atuação desses eventos, há duas épocas do ano que são mais afetadas pelas fases do ENOS, sendo elas a primavera e começo do verão, e outra ao final do outono e começo do inverno do ano subsequente. Assim, nessas épocas, as chances de chuvas acima do normal são maiores em anos de El Niño sendo favorável a produtividade das culturas de verão, como o milho, e chuvas abaixo do normal em anos de La Niña, adepta aos cultivos de inverno, como o trigo e a aveia.

Tem-se como objetivo deste, a exploração estatística dos dados pluviométricos no decorrer de 20 anos no município de Tibagi-PR, comparando-os no referido período, bem como verificando a possível relação com a produção agrícola anual de aveia, trigo e milho no município.

\section{METODOLOGIA}

Tibagi (Figura 1), município paranaense com população estimada para 2015 de 20.377 habitantes e aproximadamente $2.951 \mathrm{~km}^{2}$ de extensão (IBGE, 2015), está localizado segundo a classificação do IPARDES (2012) na Mesorregião Geográfica Centro Oriental Paranaense, Microrregião Geográfica de Telêmaco Borba. De acordo com o Mapa de clima do Paraná, elaborado pelo ITCG (2008), a classificação climática que a área de estudo recebe é do tipo $\mathrm{Cfb}$, clima de influência oceânica, com verões mais úmidos que os invernos, chuvas abundantes e bem distribuídas. Ao verificar o Sistema de Informações Hidrológicas do Instituto das Águas do Paraná (2015), constata-se que a pluviosidade anual acumulada em 2014 foi $1.545 \mathrm{~mm}$. Outra característica importante para este estudo é a pedologia, que 

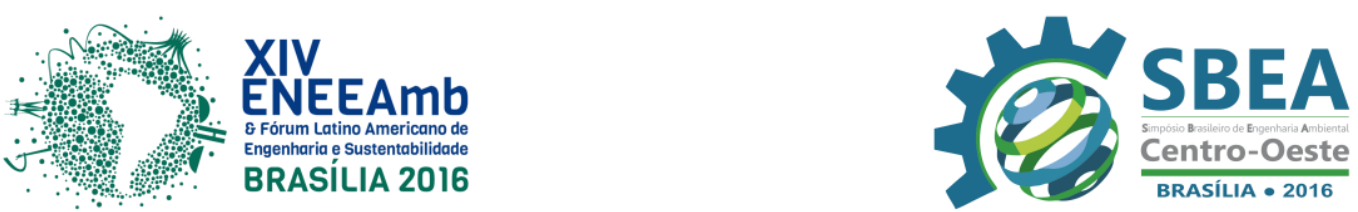

conforme a classificação do Mapa de Solos do Paraná (ITCG, 2008) tem como predominância Latossolos e resquícios de Cambissolos, garantindo bom potencial agrícola ao município.

Figura 1 - Localização da área de estudo: Tibagi-PR.

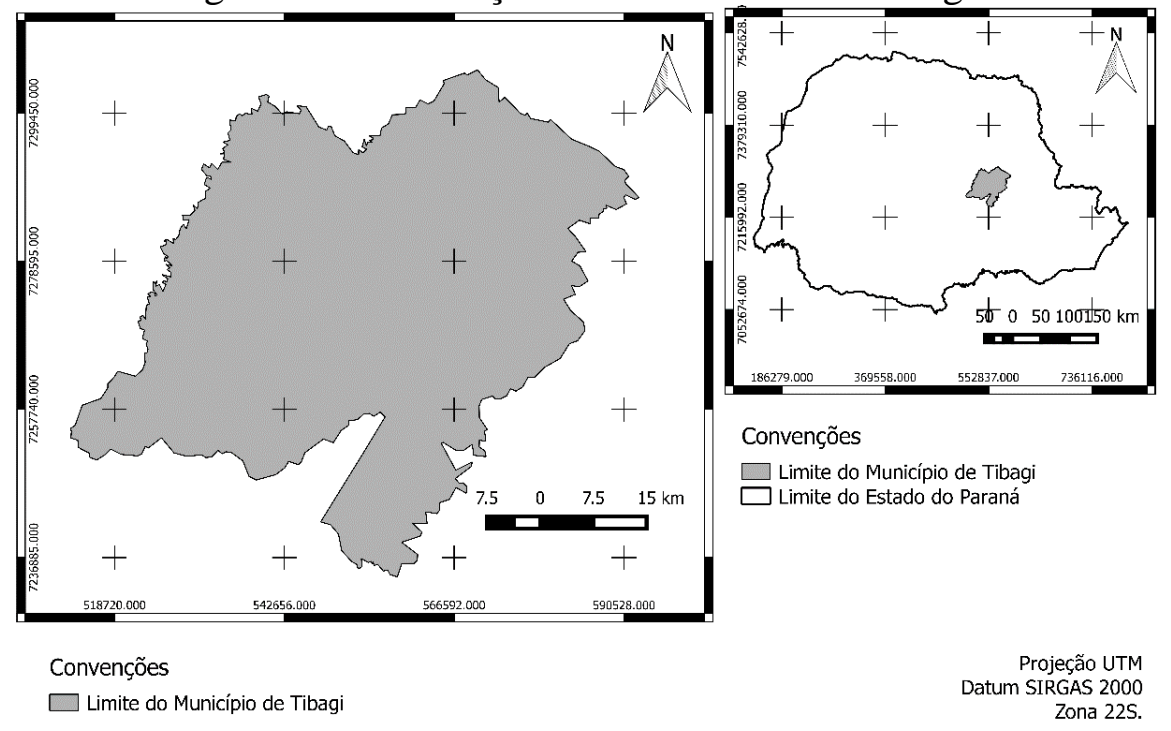

Para o levantamento dos demais dados, utilizaram-se informações pluviométricas obtidas por meio do Instituto das Águas do Paraná disposto no Sistema de Informações Hidrológicas (2015), que foram analisadas anualmente para área de estudo. A partir disso foram inseridos dados referentes a produção agrícola temporária de aveia, trigo e milho disponibilizada pelo Sistema IBGE de Recuperação Automática - SIDRA (2015), no período de 1990 a 2010 para o município de Tibagi-PR.

Tabela 1 - Série histórica em questão com suas devidas precipitações e produções de milho, trigo e aveia.

\begin{tabular}{|c|c|c|c|c|}
\hline Ano & $\begin{array}{c}\text { Precipitação } \\
(\mathrm{mm})\end{array}$ & $\begin{array}{c}\text { Produção de Milho } \\
(\mathrm{kg} / \mathrm{ha})\end{array}$ & $\begin{array}{c}\text { Produção de Trigo } \\
(\mathrm{kg} / \mathrm{ha})\end{array}$ & $\begin{array}{c}\text { Produção de Aveia } \\
(\mathrm{kg} / \mathrm{ha})\end{array}$ \\
\hline 1990 & 1722,9 & 3750 & 1700 & 1000 \\
\hline 1991 & 1374,5 & 3357 & 2600 & 900 \\
\hline 1992 & 1399,5 & 3878 & 2131 & 800 \\
\hline 1993 & 1610 & 4850 & 2323 & 1000 \\
\hline 1994 & 1059,9 & 4831 & 2539 & 800 \\
\hline 1995 & 1104,8 & 5687 & 1900 & 1514 \\
\hline 1996 & 1422 & 5638 & 2936 & 1110 \\
\hline 1997 & 1591,9 & 5655 & 2442 & 1262 \\
\hline 1998 & 1826,8 & 5941 & 2309 & 2618 \\
\hline 1999 & 1044,6 & 4990 & & 800 \\
\hline
\end{tabular}




\begin{tabular}{|c|c|c|c|c|}
\hline 2000 & 1477,3 & 6183 & 2302 & 941 \\
\hline 2001 & 1773,9 & 7482 & 3372 & 1434 \\
\hline 2002 & 1426 & 7256 & 1404 & 1046 \\
\hline 2003 & 1768,1 & 7784 & 3500 & 1598 \\
\hline 2004 & 1584,6 & 7328 & 2400 & 1137 \\
\hline 2005 & 1486,2 & 6414 & 2450 & 1400 \\
\hline 2006 & 1204 & 7402 & 2000 & 1766 \\
\hline 2007 & 1405,5 & 8429 & 2232 & 2073 \\
\hline 2008 & 1467,9 & 8615 & 3200 & 2014 \\
\hline 2009 & 1967,3 & 3779 & 2000 & 2000 \\
\hline 2010 & 1418,4 & 8789 & 3518 & 3516 \\
\hline
\end{tabular}

Em seguida, foram verificados os anos de influência e a intensidade dos eventos El Niño e La Niña neste intervalo de tempo (Tabela 2), segundo a classificação do Instituto Nacional de Pesquisas Espaciais - INPE (2015) sob o parâmetro de pluviosidade no município.

Tabela 2 - Intensidades dos fenômenos El Niño e La Niña entre 1990 e 2010.

\begin{tabular}{|c|c|c|c|c|c|}
\hline \multicolumn{3}{|c|}{ El Niño } & \multicolumn{3}{c|}{ La Niña } \\
\hline Fraco & Moderado & Forte & Fraco & Moderado & Forte \\
\hline 2004 & 1994 & 1993 & 1995 & 1998 & 2007 \\
\hline 2005 & 1995 & 1997 & 1996 & 2001 & 2008 \\
\hline 2006 & 2002 & 1998 & & & \\
\hline 2007 & 2003 & & & & \\
\hline 2009 & & & & & \\
\hline 2010 & & & & & \\
\hline
\end{tabular}

Após a coleta de dados, o primeiro teste aplicado foi para evidenciar se há diferenças ou não entre os volumes de precipitações das diferentes intensidades do evento El Niño. Estas foram comparadas (fraco, moderado e forte) no período de ocorrência dos fenômenos, utilizando-se o teste de variância não paramétrico Kruskal-Wallis, apropriado para comparar três ou mais amostras independentes, dos mesmos tamanhos ou ainda desiguais. Para o fenômeno La Niña, não foi possível executar este teste de variância pois o número de amostras foi insuficiente.

Posteriormente, compararam-se as pluviosidades dos anos com influência de El Niño, La Niña e sem ocorrência de quaisquer destes fenômenos climáticos no decorrer da série histórica. Por apresentar distribuição normal utilizou-se o teste paramétrico ANOVA (um critério). 

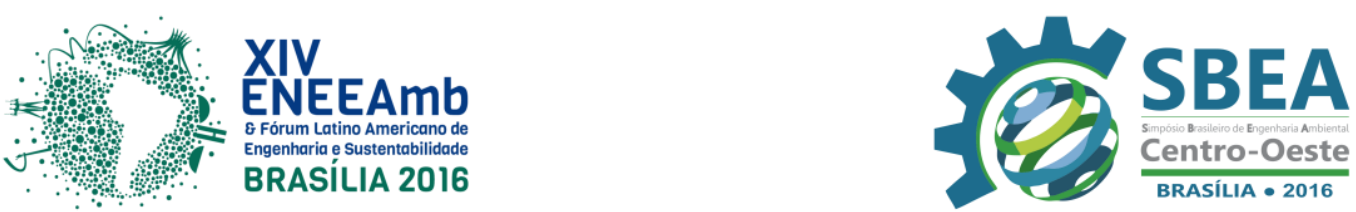

Por fim, testou-se, a correlação entre as precipitações no período de estudo com os dados de produção das culturas de milho, trigo e aveia, respectivamente, utilizando para tal o teste de correlação linear de Pearson.

Utilizou-se o software Bioestat 5.0 para gerar os testes estatísticos e gráficos.

\section{RESULTADOS E DISCUSSÕES}

De acordo com a exploração dos dados estatísticos, para o primeiro teste foi encontrado o valor de 0,2371 para $\mathrm{p}$. Como $\mathrm{p} \geq 0,05$ constata-se que não há diferença no volume de precipitação entre as intensidades do fenômeno ENOS no período estudado, ou seja, as magnitudes não interferiram na quantificação do regime de chuvas. Segundo Berlato e Fontana (2016), os impactos associados ao El Niño para o desenvolvimento da agricultura na região sul do país estão condicionados ao tipo de cultura e ao calendário agrícola em que ocorrem chuvas acima da média na região, como é o caso do município no decorrer do ano. Outro fator que pode estar relacionado com a invariabilidade entre os volumes de precipitação é o curto período de análise pluviométrica, pois maiores quantificações possibilitam analises mais precisas.

Tabela 3 - Resultados do Teste Estatístico Kruskal-Wallis.

\begin{tabular}{|c|c|}
\hline Variáveis & Resultados \\
\hline $\mathrm{H}$ & 2.8782 \\
\hline Graus de liberdade & 2 \\
\hline (p) Kruskal-Wallis & 0.2371 \\
\hline
\end{tabular}

Paro o teste de variância ANOVA (um critério) foi obtido o valor de 0,5605 para p, comprovando assim, que os eventos em questão não interferiram na precipitação entre os anos 1990 e 2010, ou seja, os anos com ocorrência de El Niño e La Niña comparados a anos sem ocorrência de quaisquer desses eventos, no período estudado, não interviram no regime pluviométrico do município de Tibagi-PR. Afere-se com esta estatística (Figura 2) que a amplitude de variação de precipitação para ENOS é muito maior comparada a precipitação dos anos sem ocorrência dos eventos.

Figura 2 - Estatística Descritiva para o teste ANOVA: um critério.

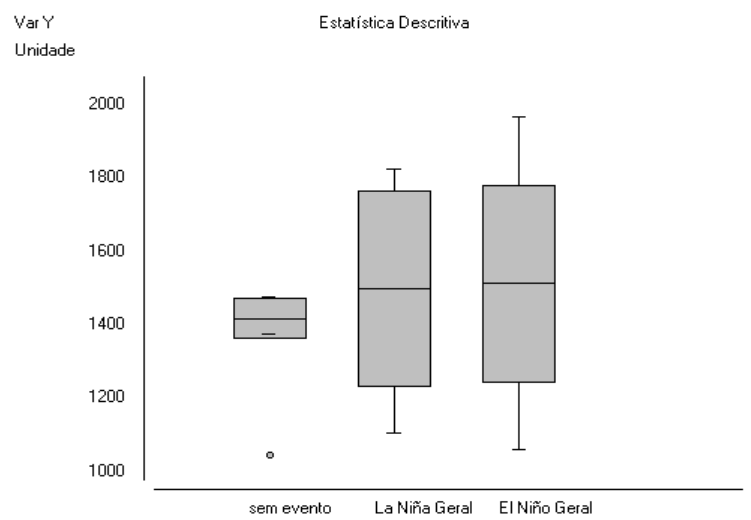



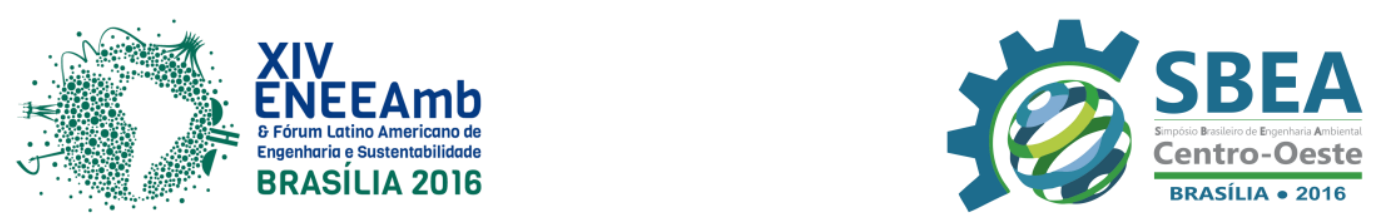

Por fim, para a correlação de Pearson foram realizadas estatísticas entre os dados de precipitação com cada uma das produções agrícolas, levando em consideração o valor estatístico de p e o coeficiente de Pearson (r) que mede o grau de relação linear entre duas variáveis quantitativas.

Diante disso (Tabela 4) o valor de p encontrado para a precipitação e a referida produção de milho foi de 0,9701 , levando a constatação de não relação entre as variáveis, enquanto o valor de $\mathrm{r}$ foi de $-0,0087$ evidenciando mais uma vez a distante afinidade entre as variáveis. Para a correlação precipitação-produção de trigo, obteve-se um p de 0,6501 e o coeficiente de Pearson $(0,1052)$ revela menor dependência entre precipitação e produção de trigo comparada à produção de milho no mesmo período. Por fim, para o cultivo de aveia, foi encontrado o valor de 0,5757 para p, indicando assim a ausência de influência da precipitação sobre a produção, já o valor de $\mathrm{r}$ foi de 0,1295 , sugerindo que ainda que seja fraca relação entre as variáveis, este foi o maior coeficiente dentre os três cultivos em estudo (Figura 3). Tanto o trigo como a aveia são cultivos típicos de inverno, cuja predominância é de volumes mais baixos de precipitação comparados ao verão, fato este que beneficia o desenvolvimento dessas culturas agrícolas.

Berlato et. al (2005) relatam que em anos de El Niño são maiores as probabilidades de alta produtividade e que o ENOS influencia na produtividade do milho porque intervém na precipitação na fase quente do evento ocasionando valores pluviométricos superiores à média climatológica enquanto a fase fria acarreta estiagem no período de desenvolvimento do milho (correspondendo ao período da primavera e início do verão).

Tabela 4 - Resultados importantes do teste de Correlação de Pearson para os cultivos analisados

\begin{tabular}{|c|c|c|c|}
\hline Variáveis & Milho & Trigo & Aveia \\
\hline $\mathrm{p}$ & 0,9701 & 0,6501 & 0,5757 \\
\hline $\mathrm{r}$ & $-0,0087$ & 0.1052 & 0,1295 \\
\hline
\end{tabular}

Figura 3 - Correlação entre Produção e Precipitação para os cultivos de milho, trigo e aveia.
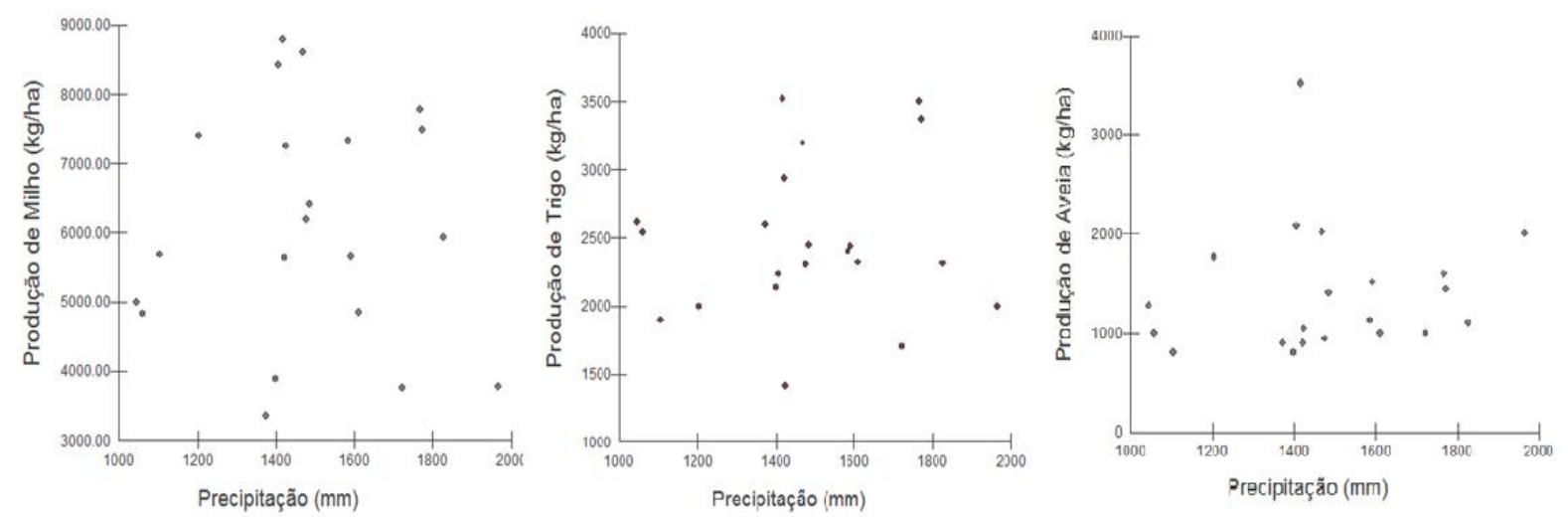

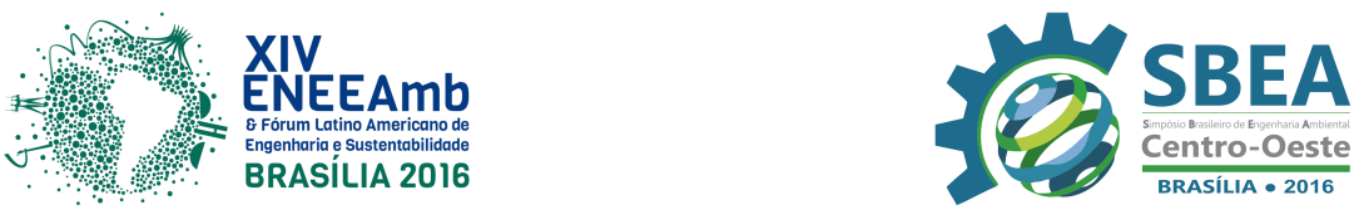

\section{CONSIDERAÇÕES FINAIS}

A partir da análise dos resultados obtidos por intermédio dos testes estatísticos, observa-se que a produção de milho, trigo e aveia do município de Tibagi-PR não se torna afetada pelos fenômenos El Niño e La Niña. Isso pode estar relacionado ao fato de as precipitações anuais do município em questão já apresentarem valores elevados, o que ofusca a interferência dos eventos. A curta série histórica também dificulta a visualização dos eventos em longa escala e ainda a relação fenômenos-precipitação, que está baseada no Índice de Oscilação Sul - IOS na qual sua classificação é generalizada pois é obtida com base na diferença de pressão entre o Pacífico Central e o Pacífico do Oeste, podendo não ser aplicada a algumas regiões.

\section{Agradecimentos}

À Universidade Tecnológica Federal do Paraná campus Campo Mourão pelo provimento dos referidos conhecimentos. À Prof ${ }^{a}$. Dr ${ }^{a}$. Maristela Moresco Mezzomo por fornecer informações referentes ao levantamento de dados, bem como o Prof $^{\circ}$. Dr ${ }^{\circ}$. Paulo Agenor Bueno por orientar este trabalho com tamanha disponibilidade e empenho.

\section{REFERÊNCIAS E CITAÇÕES}

BERLATO, Moacir Antonio et al. Associação entre El Niño Oscilação Sul e a produtividade do milho no Estado do Rio Grande do Sul. Pesq. Agropec. Bras., Brasília, v. 40, p.423-432, maio 2005.

BERLATO, Moacir Antonio; FONTANA, Denise Cybis. EI Niño e a agricultura da região sul do Brasil. 2016. 11 p. Disponível em: <http://www.cnpt.embrapa.br/pesquisa/agromet/agromet/elninolanina/elnino2.pdf $>$. Acesso em: 20 abr. 2016.

BEYRUTH, Z. Água, Agricultura e as Alterações Climáticas Globais. 2008. Revista tecnologia \& inovação agropecuária.

FERREIRA, D. B. Relações entre a variabilidade da precipitação e a produtividade agrícola de soja e milho nas regiões sul e sudeste do Brasil. 2005. São José dos Campos.

GALVANI, E.; PEREIRA, A. R.; KLOSOWSKI, É. S. Relações entre o Índice de Oscilação Sul (IOS) e o total mensal de chuva em Maringá - PR. 1998. Disponível em: $<$ http://periodicos.uem.br/ojs/index.php/ActaSciTechnol/article/view/3124/2332>. Acesso em: 17 nov. 2015.

INSTITUTO BRASILEIRO DE GEOGRAFIA E ESTATÍSTICA - IBGE. Cidades: Tibagi. $2015 . \quad$ Disponível em: $<$ http://www.cidades.ibge.gov.br/xtras/perfil.php?lang=\&codmun=412750\&search=parana|tib agi>. Acesso em: 17 nov. 2015. 

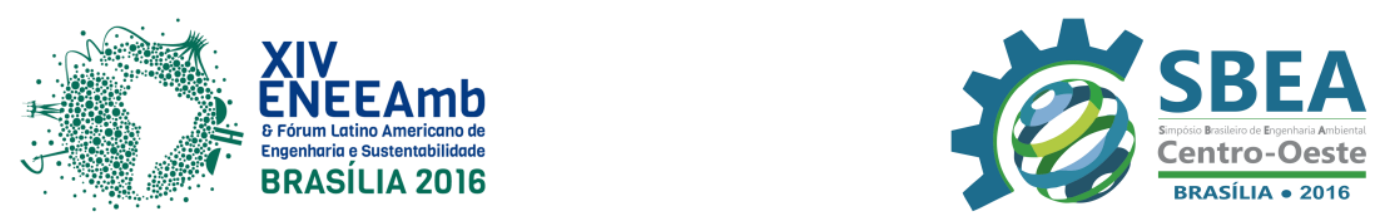

INSTITUTO DAS ÁGUAS DO PARANÁ. Alturas de precipitação - Resumo anual. 2015. Disponível em: <http://www.sih-web.aguasparana.pr.gov.br/sihweb/gerarrelatorioalturasanuaisprecipitacao.do?action=carregarinterfaceinicial $>$. Acesso em: 17 nov. 2015.

INSTITUTO NACIONAL DE PESQUISAS ESPACIAIS - INPE. Fenômeno El Niño atua com atividade moderada no oceano pacífico equatorial. 2015. Disponível em: <http://enos.cptec.inpe.br/>. Acesso em: 06 nov. 2015.

INSTITUTO PARANAENSE DE DESENVOLVIMENTO ECONÔMICO E SOCIAL IPARDES. Relação dos municípios do estado ordenados segundo as mesorregiões e as microrregiões geográficas do IBGE. 2012. Disponível em: <http://www.ipardes.gov.br/pdf/mapas/base_fisica/relacao_mun_micros_mesos_parana.pdf > . Acesso em: 17 nov. 2015.

INSTITUTO DE TERRAS, CARTOGRAFIA E GEOCIÊNCIAS - ITCG. Mapa de Clima do Estado do Paraná. 2008. Disponível em: <http://www.itcg.pr.gov.br/arquivos/File/Produtos_DGEO/Mapas_ITCG/PDF/Mapa_Climas_ A3.pdf>. Acesso em: 17 nov. 2015.

INSTITUTO DE TERRAS, CARTOGRAFIA E GEOCIÊNCIAS - ITCG. Mapa de Solos do Estado do Paraná. 2008. Disponível em: <http://www.itcg.pr.gov.br/arquivos/File/Produtos_DGEO/Mapas_ITCG/PDF/Mapa_Solos.p df>. Acesso em: 17 nov. 2015.

PAULA, G. M. de et al. Influência do fenômeno El Niño na erosividade das chuvas na região de Santa Maria (RS). 2010.

SILVA, L. L. da et al. Influência das precipitações na produtividade agrícola no Estado da Paraíba. Revista Brasileira de Engenharia Agrícola e Ambiental. 2009.

SILVA, R. R. da. Relação entre precipitação pluviométrica e produtividade da cultura de soja no município de Ibirubá-RS. 2013.93 f. Dissertação (Mestrado) - Curso de Geografia e Geociências, UFSM. RS, 2013.

SISTEMA IBGE DE RECUPERAÇÃO AUTOMÁTICA - SIDRA. Censo Agropecuário. Disponível em: <http://www.sidra.ibge.gov.br/bda/acervo/acervo9.asp?e=c\&p=CA\&z=t\&o=26> Acesso em: 18 nov. 2015. 